REVISTA DE DERECHO UNED, núm. 3, 2008

\title{
EL TRIBUNAL CONSTITUCIONAL Y LAS LIBERTADES DEL ARTÍCULO 20 DE LA CONSTITUCIÓN ESPAÑOLA ${ }^{1}$
}

Resumen: Las libertades reconocidas en el artículo 20 de la Constitución española son esenciales en un sistema democrático, sin embargo establecer su contenido y límites no siempre es tarea fácil. El Tribunal Constitucional ha sido el encargado de perfilar una abundante doctrina sobre estas libertades, delimitando su alcance, con el fin de asegurar su respeto y de hacerlas compatibles con el ejercicio de otros derechos y libertades constitucionales.

Palabras clave: Libertad de expresión; libertades informativas; límites; jurisprudencia constitucional.

Abstract: The liberties reflected in the article are basic in a democratic country, however stablish its content and limits is not easy.

Constitutional Court has been in charged to define an extense doctrine about those liberties, determinating aplication with the goal to garantee its respect and make possible to combine them with other rights and constitutional liberties.

Key words: Expression freedom, freedom to inform, limits, constitutional jurisprudence ( law of precedence/case law).

Sumario. I.- RELACIONES Y CONFUSIONES ENTRE LAS LIBERTADES DEL ARTÍCULO 20 CE.: 1.- La libertad de expresión. 2.- El derecho a la información. II.- LOS LÍMITES A ÉSTOS DERECHOS: 1.- Límites internos. 2.- Límites constitucionales. 3.- Límites a la libertad de expresión por razón del desempeño de determinadas funciones públicas: A. Funcionarios públicos. B.- Miembros de las Fuerzas Armadas. C. Fuerzas y Cuerpos de Seguridad del Estado.

1 MARÍA ACRACIA NÚÑEZ MARTÍNEZ. Profesora Colaboradora del Departamento de Derecho Político de la Facultad de Derecho. UNED. 


\section{RELACIONES Y CONFUSIONES ENTRE LAS LIBERTADES DEL ARTÍCULO $20 \mathrm{CE}$}

La libertad de expresión, y el resto de libertades reconocidas en el artículo 20 de la CE, son libertades determinantes en las sociedades democráticas. Como ha manifestado SÁNCHEZ GONZÁLEZ², no puede haber participación genuina de los miembros de la sociedad en la toma de decisiones políticas sin libertad de expresión. Las libertades informativas se constituyen en piedra angular de todo régimen político. La jurisprudencia constitucional ha declarado repetidamente que la libertad reconocida en el art. 20.1 d) C.E., en cuanto transmisión de manera veraz de hechos noticiables, de interés general y relevancia pública, no se erige únicamente en derecho propio de su titular sino en una pieza esencial en la configuración del Estado democrático, garantizando la formación de una opinión pública libre y la realización del pluralismo como principio básico de convivencia (entre la abundante jurisprudencia, SSTC 6/1981, 104/1986, 159/1986, 171/1990, 172/1990, 219/1992, 240/1992, 173/1995). En definitiva, las libertades contenidas en el art. $20 \mathrm{CE}$. se constituyen en valores objetivos esenciales del Estado democrático.

Cuando apartado $1 .^{\circ}$ de éste artículo 20 , reconoce y protege los derechos: a) a expresar y difundir libremente los pensamientos, ideas y opiniones mediante la palabra, el escrito o cualquier otro medio de reproducción. b) a la producción y creación literaria, artística, científica y técnica. c) a la libertad de cátedra, y d) a comunicar o recibir libremente información veraz por cualquier medio de difusión, cabría preguntarnos si nos encontramos ante derechos distintos y estancos, o si, por el contrario nos encontramos ante derechos que tienen un sustrato común.

Las libertades de información, prensa y opinión constituyen definiciones derivadas histórica y conceptualmente, del primigenio y fundamental derecho a la libertad de expresión de pensamientos, pudiendo existir, inicialmente una conexión subsidiaria de los derechos informativos a la libertad de expresión ${ }^{3}$, sin embargo con el devenir de los tiempos, y a pesar de las dificultades que plantea su delimitación con la libertad de expresión, la libertad de información, como libertad que tiene como objeto los hechos que pueden

¿ Sánchez González, S.- La libertad de expresión, Marcial Pons, Madrid, 1992, págs 10 a 31 .

3 Saraza Jimena, R.- Libertad de expresión e información frente a honor, intimidad y propia imagen, Editorial Aranzadi, Pamplona, 1984, págs. 161 y ss 
considerarse noticiables, ha adquirido la condición de derecho autónomo ${ }^{4}$.

Aunque algunos sectores doctrinales hayan defendido su unificación o globalización, en la Constitución se encuentran separados. Como ha indicado el TC, nos encontramos ante libertades que presentan un diferente contenido y es posible señalar también que sean diferentes sus límites y efectos, tanto ad extra como ad intra, en las relaciones jurídicas. En el art. 20 de la Constitución la libertad de expresión tiene por objeto pensamientos, ideas y opiniones, concepto amplio dentro del que deben incluirse también las creencias y los juicios de valor, mientras que el derecho a comunicar y recibir libremente información versa, en cambio, sobre hechos o, tal vez más restringidamente, sobre aquellos hechos que pueden considerarse noticiables (STC 61/1988)

No obstante, es cierto que, en los casos reales que la vida ofrece, no siempre es fácil separar la expresión de pensamientos, ideas y opiniones de la estricta comunicación informativa, pues la expresión de pensamientos necesita a menudo apoyarse en la narración de hechos y, a la inversa, la comunicación de hechos o de noticias no se da nunca en un estado químicamente puro y comprende, casi siempre, algún elemento valorativo o, dicho de otro modo, una vocación a la formación de una opinión. Por ello, el TC, aconseja, en los supuestos en que pueden aparecer entremezclados elementos de una y otra significación, atender, para calificar tales supuestos y encajarlos en cada uno de los apartados del art. 20, al elemento que en ellos aparece como preponderante.

La libertad de expresión, como derecho de los ciudadanos frente al poder, puede ser ejercida por cualquier persona física o jurídica nacional o extranjera, sin que lo expresado pueda en ningún caso ser objeto de censura, e independientemente del medio empleado para su difusión (oral, escrito, DVD...).

La comunicación informativa, a que se refiere el apartado d) del art. 20.1 de la Constitución, versa sobre hechos ${ }^{5}$, y sobre hechos, específicamente, "que pueden encerrar trascendencia pública» a efectos de que «sea real la participación de los ciudadanos en la vida colectiva», de tal forma que de la libertad de información -y del correlativo

${ }^{4}$ Rallo Lombarte, A.- Pluralismo Informativo y Constitución, Tirant Monografías, Valencia, 2000, págs. $81-82$

5 Se alinea así el TC, con el criterio mantenido por el TEDH, entre otras, STEDH caso Lingens, de 8 de julio de 1986. 
derecho a recibirla - «es sujeto primario la colectividad y cada uno de sus miembros, cuyo interés es el soporte final de este derecho" (STC 105/1983).

En la STC 47/2000, el Tribunal Constitucional ha establecido claramente esta diferencia: mientras la primera -la libertad de expresión- «tiene por objeto pensamientos, ideas y opiniones, en un concepto amplio, el derecho de información «versa, en cambio, sobre hechos» (STC 61/1998); es decir, lo que se trasmite. «En un caso es la idea y en otro la noticia o el dato" (STC 223/1992).» La conclusión anterior resulta de capital importancia, porque uno y otra comportan regímenes distintos en su relación con otros derechos con los que, en su caso, puedan entrar en colisión.

En efecto, mientras que la libertad de expresión resulta objeto de una declaración de reconocimiento y protección genérica en el art. 20.1 a) CE. sin más, el derecho a la información que reconoce y protege el párrafo d) del mismo precepto no tiene por objeto cualquier información, sino sólo la «información veraz»; dicho en otros términos empleados en esta sede en varias ocasiones (STC 223/1992), la libertad de información tiene en la veracidad un límite constitucional intrínseco.

\section{LA LIBERTAD DE EXPRESIÓN}

La libertad de expresión protege la manifestación de pensamientos, ideas y opiniones, emitidas a través de cualquier medio, y por cualquier persona, dirigida a la garantía de la libre comunicación de juicios o ideas. Mediante esta libertad se permite a cualquier sujeto la manifestación de ideologías, creencias o pensamientos sin injerencia, constituyéndose en una libertad negativa por cuanto implica la neutralidad positiva de permiso, y la no discriminación por el contenido de lo manifestado.

Junto a este contenido, en sentido estricto, de la libertad de expresión, encontramos en el Texto Constitucional otros más específicos.

El apartado 1b) del art. 20 reconoce el derecho a la producción y creación literaria, artística, científica y técnica; en definitiva, la libertad de expresión creativa.

La libertad de expresión creativa protege a la persona que crea, independientemente del medio a través del cual exprese sus creaciones. El ámbito de este derecho es muy amplio, y permite la creación bajo 
cualquier forma, convirtiéndose la forma artística, o el sistema de producción científico o técnico, en un medio adecuado de libre expresión, ya sea en una película, en una obra literaria, o en una obra teatral, su creador se halla igualmente protegido, con lo que se vienen a equiparar éstos medios con cualquier otro medio de comunicación social.

El derecho a la producción y creación literaria, artística, científica y técnica, reconocido y protegido en el apartado b) del art. $20 \mathrm{CE}$., no es sino una concreción del derecho -también reconocido y protegido en el apartado a) del mismo- a expresar y difundir libremente pensamientos, ideas y opiniones. El mencionado derecho, así como el derecho a la libertad de expresión, que supone tanto el derecho a comunicar como el derecho a recibir informaciones o ideas de toda índole por cualquier procedimiento, se hallan sujetos a las limitaciones establecidas en el art. 20.4 de la C.E.,(. STC 135/85) dra.

El apartado c) del artículo $20 \mathrm{CE}$, reconoce la libertad de cáte-

Una clara definición de lo que entendemos por libertad de cátedra la encontramos en la STC 5/81:" La libertad de enseñanza que explícitamente reconoce nuestra Constitución (art. 27.1) puede ser entendida como una proyección de la libertad ideológica y religiosa y del derecho a expresar y difundir libremente los pensamientos, ideas $\mathrm{u}$ opiniones que también garantizan y protegen otros preceptos constitucionales (especialmente arts. 16.1 y 20.1 a). Esta conexión queda, por lo demás, explícitamente establecida en el art. 9 del Convenio para la protección de los derechos humanos y de las libertades fundamentales firmado en Roma en 4 de noviembre de 1950, en conformidad con el cual hay que interpretar las normas relativas a derechos fundamentales y libertades públicas que nuestra Constitución incorpora, según dispone el artículo 10.2. En cuanto que la enseñanza es una actividad encaminada de modo sistemático y con un mínimo de continuidad a la transmisión de un determinado cuerpo de conocimientos y valores, la libertad de enseñanza, reconocida en el art. 27.1 de la Constitución implica, de una parte, el derecho a crear instituciones educativas (art. 27.6) y, de otra, el derecho de quienes llevan a cabo personalmente la función de enseñar, a desarrollarla con libertad dentro de los límites propios del puesto docente que ocupan (art. $20.1 \mathrm{c}$ ). Del principio de libertad de enseñanza deriva también el derecho de los padres a elegir la formación religiosa y moral que desean para sus hijos (art. 27.3). Se trata en todos los casos de derechos que tienen límites necesarios que resultan de su propia natura- 
leza, con independencia de los que se producen por su articulación con otros derechos o de los que, respetando siempre su contenido esencial, pueda establecer el legislador».

En lo que a la titularidad de la libertad de Cátedra se refiere, su propia denominación puede dar lugar a confusión, pues podría pensarse que es un derecho que únicamente afecta a los Catedráticos, no siendo ello así, sino que afecta a la totalidad de los docentes, como ha determinado el Tribunal Constitucional en su Sentencia 5/81: «Aunque tradicionalmente por libertad de cátedra se ha entendido una libertad propia sólo de los docentes en la enseñanza superior o, quizá más precisamente, de los titulares de puestos docentes denominados precisamente «cátedras», resulta evidente, a la vista de los debates parlamentarios, que son un importante elemento de interpretación, aunque no la determinen, que el constituyente de 1978 ha querido atribuir esta libertad a todos los docentes, sea cual fuere el nivel de enseñanza en el que actúan y la relación que media entre su docencia y su propia labor investigadora».

Si bien corresponde a todos los docentes, también es cierto que se trata de un derecho que admite modulaciones relacionadas, por un lado por el carácter público o privado del centro docente, $y$, por otro, por el nivel educativo.

En los centros docentes privados, la libertad de cátedra puede ceder ante el ideario del centro. En los centros docentes públicos, implica la ausencia de orientaciones ideológicas en la labor docente e investigadora del profesor.

En lo que se refiere al nivel educativo, aunque en la enseñanza pública es un derecho que se otorga a todos los docentes, debemos de indicar que en los niveles educativos inferiores, puede ceder ante la ordenación del sistema educativo. Se trata, por consiguiente, de un derecho que alcanza su plena eficacia en la enseñanza superior.

Como ha indicado ALZAGA VILLAAMIL ${ }^{6}$, el derecho a la libertad de cátedra parte de la libertad de investigación y consiste en la libertad que ostenta el profesor de impartir la actividad docente de acuerdo con su propio programa de la asignatura, designando libremente el material didáctico que se juzgue pertinente, junto con el reconocimiento del derecho de evaluar el aprovechamiento de sus alumnos, criterio sustentado por el Tribunal Constitucional, y por el Tribunal

6 Alzaga Villamil, O, y otros.- Derecho politico español según la Constitución de 1978, Vol. II, CERA, Madrid, 1998, págs 112 a 114. 
Supremo : «...el contenido positivo de la libertad de cátedra, en cuanto libertad de expresión docente, se extiende en el nivel educativo superior a la selección del programa de la disciplina, con todo lo que comporta en orden a su preparación por el alumno y a su evaluación ...»(Sentencia del Tribunal Supremo de 29 de octubre de 1990)

\section{EL DERECHO A LA INFORMACIÓN}

El derecho a la información cuenta con dos claras vertientes, por un lado el derecho a ser informado, sin que el Estado pueda en ningún caso manipular la información que los ciudadanos tienen derecho a conocer, al tiempo que ha de impedir que nadie pueda llegar a hacerlo. La segunda vertiente de éste derecho es la de dar a conocer a la opinión pública información veraz, libre, efectiva, objetiva y plural, de tal forma que la censura previa se halla absolutamente vetada por el Texto Constitucional. Los hechos de los que se informe han de ser ciertos, no hay lugar para la rumorología, y ha de ser enteramente plural, el ciudadano tiene el derecho a recibir la información por el medio de comunicación por él elegido, sin que quepa un único cauce de conocer la información.

La libertad de información se manifiesta como una libertad activa, el derecho a buscar y difundir información, pero también como una libertad pasiva, el derecho a recibir información.

El alcance, contenido, titularidad y exigencias de la libertad de información han sido claramente establecidos por el TC.

Ninguna duda puede caber, a este respecto, en orden a la titularidad, en el caso del derecho a comunicar información, pues éste corresponde a todas las personas (STC 6/1981, de 16 de marzo, fundamento jurídico $4 .^{\circ}$ ), aunque no fuera más que porque el proceso en que la comunicación consiste no siempre podrá iniciarse mediante el acceso directo del profesional del periodismo al hecho noticiable.

Se puede afirmar, por consiguiente, que el sujeto activo de la libertad informativa es, en sentido estricto, cualquier individuo, pero también es cierto que son los periodistas quienes encuentran en esta libertad el fundamento más importante para el ejercicio de su profesión, constituyendo el sujeto pasivo de la libertad de información la colectividad?

7 Villanueva, E.- Derecho Comparado de la información, Universidad Iberoamericana, México, 1998, pág. 28 
El titular del derecho a la información es universal, de manera que tiene derecho a la información cada una de las personas que llamamos público, de manera que el libre ejercicio de la información no corresponde exclusivamente a la empresa informativa o al profesional de la información, sino a todos, a cada una de las personas, sin excepción. ${ }^{8}$ Sin embargo, las personas que generalmente se ocupan de difundir los hechos son los periodistas. La libertad de información, implica el derecho a difundir hechos veraces en cualquiera de los medios de comunicación existentes.

Como ha indicado RALLO LOMBARTE ${ }^{9}$, el ejercicio de las libertades informativas por quienes hacen profesión de la expresión de ideas u opiniones o de la comunicación de información, ejerciéndolos con mayor frecuencia que el resto de los ciudadanos, aunque no implica ningún privilegio, pero la Constitución lo hace merecedor, como salvaguardia a quienes hacen de la búsqueda y difusión de información su profesión específica, de un notable haz de garantías jurídicoconstitucionales, depositando, en gran medida, en el profesional y en el medio de comunicación en el que desarrolla su actividad informativa, la responsabilidad de contribuir a conformar una opinión pública libre forjada en el suministro de información veraz, razón por la cual, la Constitución Española contiene una serie de derechos específicos aplicables a ellos.

El apartado $1 \mathrm{~d}$ ) del artículo 20 reconoce que la ley regulará el derecho a la cláusula de conciencia y al secreto profesional en el ejercicio de estas libertades. Se trata de dos derechos relacionados, pero diferentes.

La cláusula de conciencia se configura como un derecho de los profesionales de la información, pero encuentra su ámbito de aplicación subjetivo en derecho a la cláusula de conciencia, cuya regulación constitucional se complementó por la Ley Orgánica 2/1997, que regula las relaciones contractuales de aquéllos con las empresas de comunicación con vistas a la garantía de su propia libertad informativa.

El TC ha dictado dos importantes sentencias referentes a la cláusula de conciencia, la 199/1999 y la 225/2002. En la STC 199/1999, el TC ha manifestado: «El reconocimiento por parte del art. $20.1 \mathrm{~d}$ ) C.E. del derecho a la cláusula de conciencia no ha encontrado desa-

${ }^{8}$ Desantes Guanter, J.M. ${ }^{a}-$ El futuro de los profesionales de la información. Ed. Universidad San Sebastián, Concepción, 1999, págs. 27-28

9 Op. Cit, pág. 80 
rrollo legislativo en nuestro Ordenamiento hasta la Ley Orgánica 2/1997, de 19 de junio, lo cual no ha obstado ni a su invocación como derecho constitucional que es, ni a su regulación en algunos códigos deontológicos profesionales, estatutos de redacción o convenios colectivos, posibilidad esta última de incorporación convencional de referencias a derechos fundamentales admitida por nuestra jurisprudencia desde la STC 58/1985 y que es, justamente, el caso del presente recurso de amparo. La relación instrumental del derecho a la cláusula de conciencia respecto al ejercicio de la libertad de información resulta indispensable para determinar desde la perspectiva constitucional si ha existido o no una vulneración de tal derecho. Es respecto a los profesionales de la información donde encuentra sentido el reconocimiento del derecho a la cláusula de conciencia, como garantía de un espacio propio en el ejercicio de aquella libertad frente a la imposición incondicional de la empresa de comunicación; y también como forma de asegurar la transmisión de toda la información por el profesional del medio, contribuyendo así a preservar el pluralismo que justifica el reconocimiento del derecho. No es posible la elaboración de un catálogo cerrado de funciones cuyos titulares pudieran reclamar la cláusula de conciencia.

Consecuentemente, el reconocimiento de la cláusula de conciencia al profesional de la comunicación en el ejercicio de su libertad de información no puede entenderse exclusivamente como un derecho particular de aquél; sino, al tiempo, como garantía de que a su través se preserva igualmente la satisfacción del carácter objetivo de dicha libertad, de su papel como pieza básica en el sistema democrático y de su finalidad como derecho a transmitir y recibir una información libre y plural.

En la Sentencia 225/2002 el Tribunal Constitucional ha determinado que : «No es ocioso recordar cómo la progresiva diferenciación de la libertad de información respecto de la de expresión a medida que la transmisión de hechos y noticias ha ido adquiriendo históricamente importancia esencial, supuso no sólo el reconocimiento del derecho a la información como garantía de una opinión pública libre en un Estado democrático, sino la exigencia de evitar que su ejercicio por parte de las empresas de comunicación, generalizadas como medios de transmisión de las noticias, pudiera atentar a la finalidad del derecho o a su ejercicio por parte de aquellos profesionales que prestan servicios en ellas, titulares a su vez de la misma libertad de información. Es respecto a dichos profesionales donde encuentra sentido el reconocimiento del derecho a la cláusula de conciencia como garantía de un espacio propio en el ejercicio de aquella 
libertad frente a la imposición incondicional del de la empresa de comunicación, esto es, frente a lo que históricamente se designaba como «censura interna de la empresa periodística». Pero también como forma de asegurar la transmisión de toda la información por el profesional del medio, contribuyendo así a preservar el pluralismo que justifica el reconocimiento del derecho, reforzando las oportunidades de formación de una opinión pública no manipulada y paliando el «efecto silenciador» que, por su propia estructura, puede producir el «mercado» de la comunicación.

En consonancia con lo expuesto, no es ocioso reseñar que la Ley Orgánica 2/1997, tras configurar la cláusula de conciencia, en desarrollo de la C.E., como un derecho de los profesionales de la información que tiene por objeto garantizar la independencia en el desempeño de su función (art. 1) les reconoce la posibilidad de negarse a participar en la elaboración de informaciones contrarias a los principios éticos, de manera que :

1. El periodista tiene derecho a preservar su independencia ante situaciones de mutación ideológica desde el momento en que la considere realmente amenazada, evitando conflictos con la empresa de comunicación y riesgos de incumplimiento.

2. La protección, tan básica como tajante, ofrecida por el art. 20.1 d) CE incluye la inmediata paralización de la prestación laboral ante problemas de conciencia, incluso con carácter previo al seguimiento de cauces jurisdiccionales.

Por su parte el denominado secreto profesional implica el derecho que ostentan los periodistas a no desvelar sus fuentes de información a nadie, ni siquiera al medio de comunicación donde desempeñan su actividad laboral, temática abordada en varias sentencias del Tribunal Constitucional (SSTC 172/1990; 6/1996).

En lo que respecta al alcance, contenido y exigencias de la libertad de información, como ha indicado el TC: "La comunicación que la Constitución protege es, de otra parte, la que transmita información "veraz» (...). Cuando la Constitución requiere que la información sea "veraz" no está tanto privando de protección a las informaciones que puedan resultar erróneas -o sencillamente no probadas en juicio- cuanto estableciendo un específico deber de diligencia sobre el informador, a quien se le puede y debe exigir que lo que transmita como «hechos» haya sido objeto de previo contraste con datos objetivos, privándose, así, de la garantía constitucional a quien, defraudando el derecho de todos a la información, actúe con 
menosprecio de la veracidad o falsedad de lo comunicado. El ordenamiento no presta su tutela a esta conducta negligente, ni menos a la de quien comunique, como hechos, simples rumores o, peor aún, meras invenciones o insinuaciones insidiosas, pero sí ampara, en su conjunto, la información rectamente obtenida y difundida, aun cuando su total exactitud sea controvertible. En definitiva, las afirmaciones erróneas son inevitables en un debate libre, de tal forma que, de imponerse "la verdad» como condición para el reconocimiento del derecho, la única garantía de la seguridad jurídica sería el silencio.(STC 6/1988).

El propio Tribunal Constitucional ha venido reiterando este hecho a lo largo de varias sentencias, como la 223/1992 y la 47/2002: «Es lugar común en nuestra doctrina cuando se alude al requisito de la veracidad, que la verdad que satisface la exigencia constitucional no necesariamente ha de suponer una coincidencia exacta entre lo informado y los hechos realmente acaecidos, pues el art. 20.1 d) CE «ampara, en su conjunto, la información rectamente obtenida y difundida, aun cuando su total exactitud sea controvertible»; así pues, basta con demostrar que el informante desplegó una diligencia que pueda considerarse suficiente en relación con la averiguación o constatación de los extremos informados para entender satisfecha aquella exigencia».

En íntima relación con el requisito de veracidad de la información amparado constitucionalmente, es importante también señalar que aunque la Constitución no lo contemple expresamente, la Ley Orgánica de 26 de marzo de 1994 reconoce el denominado derecho de rectificación, como un derecho que puede ser ejercido tanto por las personas físicas como por las jurídicas, nacionales o extranjeras, a que se rectifique en el supuesto en el que hubieran dado a conocer una noticia carente de veracidad. El modo de ejercer éste derecho es a través de un comunicado, de extensión similar a la noticia que le precede, que se ha de enviar al Director del medio en el que se dio a conocer la noticia, en el plazo máximo de siete días naturales, quien habrá de dar difusión al comunicado en el plazo máximo de tres días desde la recepción del texto. Si la noticia se dio a conocer en un medio no escrito, habrá de ser dado el comunicado a conocer en un medio de difusión similar al que dio la noticia.

Otra de las características del derecho de información es que las noticias que se den a conocer sean de interés general, como ha determinado el propio Tribunal en su sentencia 57/1999: " Según se relató en los antecedentes con más detalle, el recurrente fue despedido 
por unas declaraciones a la prensa, efectuadas tras un accidente aéreo en el que habían fallecido el comandante y un piloto, declaraciones en las que exponía la existencia de irregularidades en el mantenimiento de los aviones y en determinados servicios de "Aviación Civil». Así pues, la actuación del recurrente versó sobre hechos noticiables y de interés general, y no sobre opiniones acerca de la situación expuesta, por más que la lectura de la noticia evidencia un juicio negativo sobre aquélla. Ello permite concluir que el derecho fundamental de referencia, objeto de cuestión en el presente recurso, es el de libertad de información, si se tiene en cuenta la jurisprudencia constitucional sobre las diferencias existentes entre la libertad de expresión y la libertad de información, y respectivas notas características (SSTC 6/1988, 107/1988, 105/1990, 171/1990, 172/1990, 223/1992 y 4/1996, entre otras).»

Como vertiente del derecho de información, existe el denominado derecho de información estatal, que implica que en un Estado democrático como es el nuestro, el Estado tiene la obligación de dar a conocer a la opinión pública por un lado las normas con rango de ley que son aprobadas por los órganos del Estado con capacidad normativa, cuya difusión corresponde al Boletín Oficial del Estado, por otro lado, los trabajos que se desarrollan el las diferentes Cámaras legislativas existentes en el país, y por último la obligación que tiene el Ejecutivo de difundir noticias de interés general. De esta manera, la libertad de información es, al mismo tiempo, subjetiva y difusa. Es una libertad individual de cada persona, pero también es una libertad pública que se despliega en un tejido de relaciones sociales en el que la coincidencia de intereses, de naturaleza cívica o política, puede dar lugar a acciones para la exigencia de información de los poderes públicos.

\section{LOS LÍMITES A ÉSTOS DERECHOS}

Es cierto que los derechos fundamentales no son absolutos, pero no lo es menos que tampoco puede atribuirse dicho carácter a los límites a que ha de someterse el ejercicio de los mismos. Todas las normas relativas a tales derechos se integran en un único ordenamiento inspirado por los mismos principios; y tanto los derechos individuales como sus limitaciones, en cuanto éstas derivan del respeto a la ley y a los derechos de los demás, son igualmente considerados por el art. 10.1 de la Constitución como «fundamento del orden político y de la paz social». Se produce así, en definitiva, un régimen de concurrencia 
normativa, no de exclusión, de tal modo que tanto las normas que regulan el derecho fundamental como las que establecen límites a su ejercicio vienen a ser igualmente vinculantes y actúan recíprocamente. Como resultado de esta interacción, la fuerza expansiva de todo derecho fundamental restringe, por su parte, el alcance de las normas limitadoras que actúan sobre el mismo; de ahí la exigencia de que los límites de los derechos fundamentales hayan de ser interpretados con criterios restrictivos y en el sentido más favorable a la eficacia y a la esencia de tales derechos. (STC 254/1988)

Hoy en día, tanto en la doctrina, como la jurisprudencia constitucional ha admitido que no existen derechos ilimitados, sino que todo derecho tiene sus límites (STC 11/1981, de ocho de abril). No existen derechos o libertades absolutas, de manera que las libertades contenidas en el art. $20 \mathrm{CE}$. también están sometidas a determinadas limitaciones.

Sin embargo no todos los límites tienen el mismo origen, de manera que, en la determinación de los límites a que están sometidos los derechos reconocidos en el art. $20 \mathrm{CE}$, es necesario hacer determinadas distinciones.

\section{LIMITES INTERNOS}

Límites internos son aquellos que derivan del propio concepto del derecho y de las facultades que de él se derivan.

La estrecha relación que mantienen las libertades estudiadas y el Estado democrático de Derecho, determina que no pueda admitirse en un Estado democrático como es el nuestro ni la censura previa ni el secuestro informativo.

Como libertades negativas que exigen la mayor abstención pública en cuanto a sus manifestaciones, en democracia no se puede permitir que ningún medio de comunicación pueda ser sometido a ningún tipo de control previo a su salida al mercado por autoridad política alguna, algo que el tribunal Constitucional ha reconocido en sus sentencias 52/83, y 13/85, señalando la prohibición de censura previa y manifestando que por tal: «...puede entenderse cualesquiera medidas limitativas de la elaboración o difusión de una obra del espíritu, especialmente al hacerlas depender del previo examen oficial de su contenido, y siendo ello así parece prudente estimar que la Constitución, precisamente por lo terminante de su expresión, dispone eliminar todos los tipos imaginables de censura previa, aun los 
más débiles y sutiles, que ... tengan por efecto no ya el impedimento o prohibición, sino la simple restricción de los derechos de su art. 20.1, de lo que se infiere...»

Existe por lo tanto una primera limitación que se ejerce sobre estos derechos, que implica la prohibición de injerencia pública. Hablaríamos en este caso de un elemento previo de libertad para el ejercicio de estas libertades.

\section{LÍMITES CONSTITUCIONALES}

Junto a esta limitación previa y primaria, los derechos y libertades reconocidos en el art. $20 \mathrm{CE}$ están sometidos a límites constitucionalmente reconocidos.

La primera de las limitaciones -limitación general- es la no vulneración de aquellos derechos contenidos en el Título Primero, y en la totalidad de las leyes que vengan a desarrollarlos. Esta limitación ha sido reiterada por el propio Tribunal en su sentencia del 16 de marzo de 1981: «El artículo 20 garantiza el mantenimiento de una comunicación libre sin la cual quedarían vaciados de contenido real otros derechos que reconoce la $\mathrm{CE}$ y las instituciones representativas. Asimismo, quedaría falseado el principio de legitimidad democrática que enuncia el artículo 1.2 de la $\mathrm{CE}$ y que es base de toda nuestra ordenación jurídica».

Lo que el Texto Constitucional rechaza es la comunicación de hechos no verídicos que vulnere alguno de los derechos contenidos en el citado Título Primero, por lo que si el contenido de la comunicación es real y probado, no se va a producir ningún tipo de vulneración, y éstos se van a ver reforzados.

La segunda de las limitaciones es que la comunicación no vulnere ninguno de los denominados derechos de la esfera privada: el derecho al honor, a la intimidad y a la propia imagen.

Los derecho no son absolutos, y con frecuencia entran en colisión unos con otros, es por ello, que ha sido establecido tanto doctrinal como jurisprudencialmente que en caso de que se produzca una colisión entre la libertad de información y los derechos de la esfera privada habrán de prevalecer éstos sobre aquel. La limitación podría parecer indiscutible, pero, el propio Tribunal Constitucional ha determinado en varias sentencias, que si se cumplen tres requisitos habrá de prevalecer la libertad de comunicación. Lo tres requisitos serían: 
- Veracidad de la información.

- Personalidad pública o implicación en asuntos de relevancia pública de las personas implicadas.

- Que la información vertida sobre las personas implicadas sea considerada de interés general o social.

El Tribunal Constitucional ha tenido ya numerosas oportunidades de afirmar que, en el conflicto entre las libertades reconocidas en el art. 20 C.E., de expresión e información, por un lado, y otros derechos y bienes jurídicamente protegidos, no cabe considerar que sean absolutos los derechos y libertades contenidos en la Constitución, pero, tampoco puede atribuirse ese carácter absoluto a las limitaciones a que han someterse esos derechos y libertades (STC 159/1986, caso Egin). En lo que se refiere al derecho al honor, y su relación con el derecho de información veraz, ciertamente los preceptos del Código Penal conceden una amplia protección a la buena fama y honor de las personas y a la dignidad de las instituciones, mediante la tipificación de los delitos de injurias, calumnias o desacato, en sus diversas variantes: y no es menos cierto que tal protección responde a valores constitucionalmente consagrados, vinculados a la dignidad de la persona y a la seguridad pública y defensa del orden constitucional. Pero también ha de considerarse que la formación de una opinión pública libre aparece como una condición para el ejercicio de derechos inherentes a un sistema democrático, por lo que el derecho a la información no sólo protege un interés individual, sino que entraña «el reconocimiento y garantía de una institución política fundamental, que es la opinión pública, indisolublemente ligada con el pluralismo político» (entre otras, STC 104/1986).

En consecuencia, a la hora de aplicar los tipos penales que suponen un límite al ejercicio de las libertades de expresión e información, el órgano jurisdiccional deberá, no estimar preponderante en todo caso uno de los derechos en cuestión (protegiendo siempre la buena fama afectada, o el derecho a informar o a expresarse libremente), sino, habida cuenta de las circunstancias, ponderar si la actuación del informador se ha llevado a cabo dentro del ámbito protegido constitucionalmente, o, por el contrario, si se ha transgredido ese ámbito. Pues, en tanto la labor del informador se atenga a los fines y objetivos constitucionalmente previstos, no podrá considerarse que han afectado ilegítimamente la buena fama o el honor de una persona, o el prestigio de una institución de modo que quepa una sanción penal al respecto. 
Tal ponderación corresponde sin duda al órgano jurisdiccional que conozca de las alegadas vulneraciones al honor, pero el Tribunal Constitucional, por un lado, ha señalado que entra dentro de su jurisdicción revisar la adecuación de la ponderación realizada por los Jueces, con el objeto de conceder el amparo si el ejercicio de la libertad reconocido en el art. 20 se manifiesta constitucionalmente legítimo, o denegarlo en el supuesto contrario (STC 107/1988). Y, por otro lado, en la jurisprudencia constitucional, se han ido perfilando varios criterios para llevar a cabo esa ponderación, de los que conviene subrayar los siguientes (STC 105/1990):

A) El Tribunal ha diferenciado la amplitud de ejercicio de los derechos reconocidos cn el art. 20 según se trate de libertad de expresión (en el sentido de la emisión de juicios y opiniones) y libertad de información (en cuanto a la manifestación de hechos). Con relación a la primera, al tratarse de la formulación de opiniones y creencias personales, sin pretensión de sentar hechos o afirmar datos objetivos, dispone de un campo de acción que viene sólo delimitado por la ausencia de expresiones indudablemente injuriosas sin relación con las ideas $u$ opiniones que se expongan, y que resulten innecesarias para la exposición de las mismas: campo de acción que se amplia aún más en el supuesto de que el ejercicio de la libertad de expresión afecte al ámbito de la libertad ideológica garantizada por el art. 16.1. C.E. (STC 20/1990). Por el contrario, cuando se persigue, no dar opiniones, sino suministrar información sobre hechos que se pretenden ciertos, la protección constitucional se extiende únicamente a la información veraz: requisito de veracidad que no puede, obviamente exigirse de juicios o evaluaciones personales y subjetivas. Ciertamente, resultará en ocasiones difícil o imposible separar, en un mismo texto, los elementos informativos de los valorativos: en tal caso habrá de atenderse al elemento predominante.

B) Como segundo criterio de interés, el Tribunal ha destacado que la protección constitucional de los derechos del art. 20 opera con su máxima eficacia cuando el ejercicio de los derechos de expresión e información versa sobre materias que contribuyen a la formación de una opinión pública libre, como garantía del pluralismo democrático. En consecuencia, y como también ha señalado el Tribunal, la protección constitucional de la libertad de información se reduce si esta «no se refiere a personalidades públicas que, al haber optado libremente por tal condición, deben soportar un cierto riesgo de una lesión de sus derechos de la personalidad» (STC 165/1987) por lo que en correspondencia, se debilitaría la eficacia de tal protec- 
ción en los supuestos de información u opinión sobre conductas privadas carentes de interés público.

C) Los cauces por los que se difunde la información aparecen así como relevantes para determinar su protección constitucional: «...también según la doctrina de este Tribunal (STC 165/1987), la protección constitucional de los derechos de que se trata "alcanza un máximo nivel cuando la libertad es ejercitada por los profesionales de la información a través del vehículo institucionalizado de formación de la opinión pública que es la prensa, entendida en su más amplia acepción».

D) En la exposición de criterios jurisprudenciales aplicables, conviene destacar uno de ellos, y que resulta ahora de especial interés: El relativo a la veracidad de la información como requisito para su protección constitucional. $\mathrm{El}$ art. $20.1 \mathrm{~d}$ ) C.E. reconoce y protege el derecho a comunicar libremente información veraz. La precisión de qué debe entenderse por veracidad cobra así notable trascendencia para determinar si la conducta del informador responde al ejercicio de un derecho constitucional, o se sitúa fuera de él, y por el contrario, dentro del ámbito de conductas tipificadas por las normas penales. Y, a este respecto, este Tribunal ha precisado -siguiendo en esto la doctrina de órganos jurisdiccionales de otros países- que ello no significa que quede exenta de toda protección la información errónea o no probada. Lo que el requisito constitucional de veracidad viene a suponer es que el informador tiene -si quiere situarse bajo la protección del art. $20.1 \mathrm{~d}$ )- un especial deber de comprobar la veracidad de los hechos que expone, mediante las oportunas averiguaciones, y empleando la diligencia exigible a un profesional. Puede que, pese a ello, la información resulte errónea, lo que obviamente, no puede excluirse totalmente. Pero, como señaló la Sentencia 6/1988, de 21 de enero, "las afirmaciones erróneas son inevitables en un debate libre, de tal forma que de imponerse "la verdad», como condición para el reconocimiento del derecho, la única garantía de la seguridad jurídica sería el silencio». "Información veraz» en el sentido del art. $20.1 \mathrm{~d})$, significa, pues, información comprobada según los cánones de la profesionalidad informativa, excluyendo invenciones, rumores o meras insidias.

E) Respecto a la actuación del informador, o del titular de la información, también el TC ha afirmado que : "La crítica de una conducta que se estima comprobada de un personaje público puede ciertamente resultar penosa - y a veces extremadamente penosa- para éste, pero en un sistema inspirado en los valores democráticos, la su- 
jeción a esa crítica es parte inseparable de todo cargo de relevancia pública. En este contexto, es claro que se trata -independientemente de la justicia de las apreciaciones realizadas de evaluaciones de una actuación concreta, y no de meros insultos o descalificaciones de su función pública dictadas por un ánimo vejatorio o la enemistad pura y simple.(...). Pues, ciertamente, una cosa es efectuar una evaluación personal, por desfavorable que sea, de una conducta (evaluación que se inserta en el derecho de libre expresión, y que es a veces de difícil o imposible separación de la mera información) y otra cosa muy distinta es emitir expresiones, afirmaciones, o calificativos claramente vejatorios desvinculados de esa información, y que resultan proferidos, gratuitamente, sin justificación alguna, en cuyo caso cabe que nos hallemos ante la mera descalificación, o incluso el insulto y sin la menor relación con la formación de una opinión pública libre. (...) Los insultos... no tienen nada que ver con la crítica, por dura que sea, de una conducta, sino que aparecen como meras exteriorizaciones de sentimientos personales ajenos a la información sobre hechos o a la formación de una opinión pública responsable. Se colocan por tanto, fuera del ámbito constitucionalmente protegido de la libre expresión, y representan en consecuencia la privación, a una persona (investida de autoridad, y con ocasión del ejercicio de sus funciones) de su honor y reputación al ser vejada verbalmente en un medio de gran audiencia, por supuestos defectos físicos, morales o intelectuales; sacrificio éste que no se ve justificado por la defensa de ningún bien constitucionalmente protegido y que, en cambio, y a la vista de los arts. 10.1, y 18 de la Constitución, lesiona derechos constitucionalmente protegidos del destinatario de tales expresiones insultantes.

En la Sentencia172/1990, el Tribunal Constitucional ha establecido que, además de que la comunicación a la opinión pública, sea veraz, para que prevalezca la libertad de expresión, debe resultar necesaria en función del interés público del asunto sobre el que se informa:

1. Cada información periodística constituye un acto individual de ejercicio del derecho de libertad de información que debe ser objeto del tratamiento jurídico que le corresponda, de acuerdo con las expresiones, afirmaciones o valoraciones que en la misma se contengan y el grado de cumplimiento de las reglas de veracidad e interés general que lo rigen.

2. Según reiterada doctrina constitucional, las libertades del art. 20 C.E. no sólo son derechos fundamentales de cada ciudadano, sino también condición de existencia de la opinión pública 
libre, indisolublemente unida al pluralismo político, que es un valor fundamental y requisito de funcionamiento del Estado democrático. Esta excepcional trascendencia otorga a las expresadas libertades un valor de derecho prevalente sobre los derechos de la personalidad garantizados por el art. 18.1 C.E., en los que no concurre esa dimensión de garantía de la opinión pública libre y del principio de legitimidad democrática.

3. La legitimidad de las intromisiones en el honor e intimidad personal requiere, no sólo que la información cumpla la condición de veracidad, sino también que su contenido se desenvuelva en el marco del interés general del asunto al que se refiere, puesto que, de otra forma, el derecho de información se convertiría en una cobertura formal para, excediendo del discurso público en el que debe desenvolverse, atentar sin límite alguno y con abuso de derecho al honor y a la intimidad de las personas, con afirmaciones, expresiones o valoraciones que resulten injustificadas por carecer de valor alguno en relación con el interés general del asunto.

4. Es de especial importancia distinguir entre pensamientos, ideas, opiniones y juicios de valor, de un lado, y hechos, del otro, puesto que tal distinción delimita teóricamente el respectivo contenido de los derechos de libre expresión y de información, siendo propio de este último la recepción y comunicación de hechos. Esta mezcla de descripción de hechos y opiniones, que ordinariamente se produce en las informaciones, determina que la veracidad despliegue sus efectos legitimadores en relación con los hechos, pero no respecto de las opiniones que las acompañen o valoraciones que de los mismos se hagan, puesto que las opiniones, creencias personales o juicios de valor no son susceptibles de verificación y ello determina que el ámbito de protección del derecho de información quede delimitado, respecto de esos elementos valorativos, por la ausencia de expresiones injuriosas, -que resulten innecesarias para el juicio crítico.

5. También merece distinto tratamiento el requisito de la veracidad, según se trate del derecho al honor o del derecho a la intimidad, ya que, mientras la veracidad funciona, en principio, como causa legitimadora de las intromisiones en el honor, si se trata del derecho a la intimidad, actúa, en principio, en sentido diverso. El criterio para determinar la legitimidad o ilegitimidad de las intromisiones en la intimidad de las personas no es 
el de la veracidad, sino exclusivamente el de la relevancia pública del hecho divulgado.

La libertad de información es, en términos constitucionales, un medio de formación de opinión pública en asuntos de interés general, cuyo valor de libertad preferente sobre otros derechos fundamentales viene determinado por su condición de garantía de la opinión pública, que es una institución consustancial al Estado democrático que los poderes públicos tienen especial obligación de proteger. Este valor preferente alcanza su máximo nivel cuando la libertad es ejercitada por los profesionales de la información a través del vehículo institucionalizado de formación de la opinión pública, que es la prensa, entendida en su más amplia aceptación.

Esto, sin embargo, no significa que la misma libertad no deba ser reconocida en iguales términos a quienes no ostentan igual cualidad profesional, pues los derechos de la personalidad pertenecen a todos sin estar subordinados a las características personales del que ejerce, sino al contenido del propio ejercicio, pero sí significa que el valor preferente de la libertad declina cuando su ejercicio no se realiza por los cauces normales de formación de la opinión pública, sino a través de medios, tan anormales e irregulares como es la difusión de hojas clandestinas, en cuyo caso debe entenderse, como mínimo, que la relación de preferencia que tiene la libertad de información respecto al derecho al honor se invierte a favor de este último, debilitando la eficacia justificadora de aquélla frente a lesiones inferidas a éste. La misma inversión se produce si la información no se refiere a personalidades públicas que, al haber optado libremente por tal condición, deben soportar un cierto riesgo de una lesión de sus derechos a la personalidad, sino a personas privadas que no participan voluntariamente en la controversia pública, pues en este supuesto el derecho al honor alcanza su más alta eficacia de limite de las libertades reconocidas en el art. 20 de la Constitución, que le confiere el núm. 4 del mismo artículo.

A todo ello procede añadir que la libertad de información, al menos la que incide en el honor de personas privadas, debe enjuiciarse sobre la base de distinguir radicalmente, a pesar de la dificultad que comporta en algunos supuestos, entre información de hechos y valoración de conductas personales y, sobre esta base, excluir del ámbito justificador de dicha libertad las afirmaciones vejatorias para el honor ajeno en todo caso innecesarias para el fin de la formación pública, en atención al cual se garantiza constitucionalmente su ejercicio. (STC 165/1987) 
Pero las libertades informativas no sólo guardan una estrecha relación con los derechos pertenecientes a la esfera privada (honor e intimidad). La relación existente entre las libertades de expresión e información y la libertad ideológica, también ha sido puesta de manifiesto por el TC en su sentencia $20 / 1990^{10}$. Lo que nos permitiría hablar de una tercera limitación al ejercicio del derecho a la libre expresión de ideas y opiniones.

Como indica el TC, desde su dimensión constitucional, hay que tener presente que sin la libertad ideológica consagrada en el art. 16.1 de la Constitución, no serían posibles los valores superiores de nuestro ordenamiento jurídico que se propugnan en el art. 1.1 de la misma para constituir el Estado social y democrático de derecho que en dicho precepto se instaura. Para que la libertad, la justicia, la igualdad y el pluralismo político sean una realidad efectiva y no la enunciación teórica de unos principios ideales, es preciso que a la hora de regular conductas y, por tanto, de enjuiciarlas, se respeten aquellos valores superiores sin los cuales no se puede desarrollar el régimen democrático que nos hemos dado en la Constitución de 1978. No se trata, naturalmente, de que la libertad ideológica en su manifestación externa a través de un artículo periodístico, pueda ser utilizada para eludir los límites que a la libertad de expresión impone el art. 20.4 de la Constitución, pero la visión globalizada de ambos derechos, o de las limitaciones con que han de ser ejercidos, no puede servir solamente «de interés para graduar el alcance de la faceta injuriosa del escrito e individualizar la pena»,(...), sino que han de servir también y principalmente para determinar si la «faceta injuriosa», puede o debe desaparecer ante la protección a la libertad ideológica del autor que

${ }^{10} \mathrm{La}$ Sentencia tiene como antecedente un artículo que bajo el rótulo «Spain is not different?», y que ha dado lugar a resoluciones judiciales contradictorias -absolutoria una y de condena otra- formaba una mínima parte del artículo titulado «Junio de los mundiales agosto de las multinacionales» que, escrito por el recurrente en amparo, fue publicado en el núm. 270 de la revista "Punto y Hora», correspondiente a la semana del 18 al 22 de junio de 1982 . En él se hacía una crítica adversa de la organización, medios y fines del Campeonato del Mundo de Fútbol próximo a celebrarse en España. La crítica, expresada ciertamente con dureza, exponía desde diferentes ángulos -histórico, político, social, deportivo y económico- el criterio del autor sobre este tipo de acontecimientos que, mezclando el mundo de los grandes negocios con las masivas aficiones deportivas y poniendo de relieve el multimillonario número de espectadores que, merced a los medios de comunicación social, se consigue, brindan una oportunidad muy importante y sirven de caja de resonancia mundial para que, a través de estos acontecimientos, se lleve a cabo una desorbitada propaganda política del país en que se celebran y de sus dirigentes y, a la vez, sirve de pingües negocios a los organizadores y a las multinacionales que con ese fin los patrocinan. Todo ello, además de contener insultos o agravios al Jefe del Estado español. 
consagra el art. 16.1 de la Constitución. Hay, pues, que partir de este derecho fundamental y no entenderlo simplemente absorbido por las libertades de expresión e información del art. 20.

El TC destaca la máxima amplitud con que la libertad ideológica está reconocida en el art. 16.1 de la Constitución, por ser fundamento, juntamente con la dignidad de la persona y los derechos inviolables que le son inherentes, según se proclama en el art. 10.1, de otras libertades y derechos fundamentales y, entre ellos, los consagrados en el art. 20.1, apartados a) y d), de la Norma fundamental, en su íntima conexión con la libertad ideológica.

Pues bien, respecto de estos otros derechos se ha pronunciado reiteradamente el Tribunal Constitucional, estableciendo una doctrina que, referida a supuestos que guardan cierta similitud con el caso ahora enjuiciado -límites penales al ejercicio de los derechos del art. 20-, podemos resumir en la siguiente forma:

a) Desde las SSTC 6/1981 y 12/1982, hasta las SSTC 104/1986 y 159/1986, viene sosteniendo el Tribunal que «las libertades del art. 20 (STC 104/1986) no son sólo derechos fundamentales de cada ciudadano, sino que significan el reconocimiento y la garantía de una institución política fundamental, que es la opinión pública libre, indisolublemente ligada con el pluralismo político que es un valor fundamental y un requisito del funcionamiento del Estado democrático» (STC 12/1982) o, como se dijo ya en la STC 6/1981: «El art. 20 de la Constitución, en sus distintos apartados, garantiza el mantenimiento de una comunicación pública libre, sin la cual quedarían vaciados de contenido real otros derechos que la Constitución consagra, reducidas a formas hueras las instituciones representativas y absolutamente falseado el principio de legitimidad democrática que enuncia el art. 1.2 de la Constitución, y que es la base de toda nuestra ordenación jurídico-política». En el mismo sentido se pronuncia la STC 159/1986, al afirmar que "para que el ciudadano pueda formar libremente sus opiniones y participar de modo responsable en los asuntos públicos, ha de ser también informado ampliamente de modo que pueda ponderar opiniones diversas e incluso contrapuestas". Y recordando esta Sentencia la doctrina expuesta, insiste en que los derechos reconocidos por el art. 20, no sólo protegen un interés individual sino que son garantía de la opinión pública libremente formada, «indisolublemente ligada con el pluralismo político».

b) La posición preferente que, por la doctrina expuesta y en razón de su dimensión institucional, ha de reconocerse a los derechos con- 
sagrados en el art. 20 de la Constitución, y -añadimos-, al menos por la misma razón a la libertad ideológica que garantiza el art. 16.1, implica de una parte -como dicen las SSTC 159/1986 y 51/1989-, "una mayor responsabilidad moral y jurídica en quien realiza la infracción, pero de otra exige una rigurosa ponderación de cualquier norma o decisión que coarte su ejercicio». Por ello, cuando la libertad de expresión entre en conflicto con otros derechos fundamentales e incluso con otros intereses de significativa importancia social y política respaldados, como ocurre en este caso, por la legislación penal, las restricciones que de dicho conflicto pueden derivarse deben ser interpretadas de tal modo que el derecho fundamental no resulte desnaturalizado.

c) Con base en la doctrina expuesta, las SSTC 107/1988 y 51/1989, declaran que el reconocimiento constitucional de las libertades de expresión y de comunicar y recibir información ha modificado profundamente la problemática de los delitos contra el honor en aquellos supuestos en que la acción que incide en este derecho haya sido realizada en ejercicio de dichas libertades. La dimensión constitucional de éstas "convierte en insuficiente el criterio del "animus iniurandi», tradicionalmente utilizado por la jurisprudencia penal en el enjuiciamiento de dicha clase de delitos». Y esta insuficiencia dimana de que, como ya hemos visto, los derechos fundamentales que consagra el art. 20 de la Constitución, y también por la misma razón las libertades que garantiza el art. 16.1 exceden del ámbito personal por su dimensión institucional y porque significan el reconocimiento y la garantía de la opinión pública libre y, por tanto, del pluralismo político propugnado por el art. 1.1 de la Constitución como uno de los valores superiores de nuestro ordenamiento jurídico.

En relación al caso, el TC determina que aunque la crítica que preside el artículo que se cuestiona es rechazable moral y socialmente por innecesaria, injusta y contradictoria,, no puede ser sancionada con una condena penal sin vulnerar las libertades invocadas por el recurrente que, entendiendo hacer uso de las mismas dada la relevancia que desempeñan para la efectividad del régimen democrático y la amplitud con que por tal razón han sido interpretadas por la doctrina de este Tribunal, porque, de lo contrario, se ve privado de su libertad y de su profesión por expresar de forma censurable en el ámbito político y social, sus propias ideas, criterios y sentimientos. La libertad ideológica indisolublemente unida al pluralismo político que, como valor esencial de nuestro ordenamiento jurídico propugna la Constitución, exige la máxima amplitud en el ejercicio de aquélla y, naturalmente, no sólo en lo coincidente con la Constitución y con el resto 
del ordenamiento jurídico, sino también en lo que resulte contrapuesto a los valores y bienes que en ellos se consagran, excluida siempre la violencia para imponer los propios criterios, pero permitiendo la libre exposición de los mismos en los términos que impone una democracia avanzada. De ahí la indispensable interpretación restrictiva de las limitaciones a la libertad ideológica y del derecho a expresarla, sin el cual carecería aquélla de toda efectividad. (STC 20/1990).

La cuarta de las limitaciones es que el contenido de la comunicación no resulte lesivo ni para la juventud ni para la infancia. Respecto a la infancia los niños son más fácilmente manipulables que los jóvenes, con lo que el control sobre lo que ven y lo que leen debería ser más riguroso que con éstos, aunque aún así los poderes públicos han de velar por que lo que llegue a sus manos no les perjudique.

\section{LÍMITES A LA LIBERTAD DE EXPRESIÓN POR RAZÓN DEL DESEMPEÑO DE DETERMINADAS FUNCIONES PÚBLICAS}

El TC ha tenido ocasión de pronunciarse reiteradamente sobre la existencia de límites a la libertad de expresión como consecuencia del especial celo, o la trascendencia, en el ejercicio de determinadas funciones públicas, constitucionalmente reconocidas. A través de la jurisprudencia constitucional podemos establecer una primera limitación general a la libertad de expresión por razón del cargo, referida a los funcionarios públicos, y dos limitaciones específicas, en base a las labores constitucionalmente atribuidas, $\mathrm{y}$ al régimen interno a que están sometidas, referidas a los miembros de las Fuerzas Armadas, y a las Fuerzas y Cuerpos de Seguridad del Estado.

\section{A. Funcionarios públicos}

Ciertos funcionarios públicos pueden tener limitado el derecho a la libertad de expresión en virtud de el cargo que desempeñan dentro de la administración pública, como ha dejado patente el propio Tribunal en varias de sus sentencias, aunque bien es verdad que en épocas anteriores las limitaciones de éste colectivo eran mucho mayores que en la actualidad. En varias sentencias (SSTC 69/1989, la $81 / 1983$, la $371 / 1993$ o la 69/1989) ha abordado el TC esta materia. Como indica el Máximo Intérprete constitucional: «El fondo del 
asunto consiste en la ponderación del ejercicio que un funcionario público ha hecho de determinados derechos que la Constitución le reconoce. En una primera etapa del constitucionalismo europeo, simultánea a la construcción de un modelo de burocracia creciente, pero no debidamente racionalizada, solía exigirse a los funcionarios públicos una fidelidad silente y acrítica respecto a instancias políticas superiores $y$, por consiguiente, una renuncia (cuando no se regulaban prohibiciones expresas) al uso de determinadas libertades y derechos, todo lo cual había de admitirse si no quería el funcionario caer en la temida situación del cesante. En la actualidad, y en concreto en nuestro país al menos a partir de la entrada en vigor de la Constitución de 1978, la situación es muy distinta. Conquistas históricas como la racionalización del ingreso en la función pública, como la inamovilidad del funcionario en su empleo, así como la consagración constitucional de los principios del art. 103.1 y 3, y la de los derechos de los arts. 23.2, 20.1 a) y 28.1 de la C. E., son factores que de forma convergente contribuyen a esbozar una situación del funcionario en orden a la libertad de opinión (...) mucho más próxima a la del simple ciudadano. También éste en el ejercicio de sus derechos fundamentales y libertades públicas encuentra límites, pues en ningún derecho carece de ellos, pero el funcionario se encuentra, además, con otros límites derivados de su condición de tal. Como por otra parte no todos los funcionarios cumplen los mismos servicios ni todos los Cuerpos poseen un mismo grado de jerarquización ni de disciplina interna, todos esos y otros factores (como, por ejemplo, que el funcionario actúe en su cualidad de tal o en su condición de simple ciudadano) han sido tenidos en cuenta por la jurisprudencia de otros países para determinar hasta dónde deben llegar las restricciones a algunos derechos y libertades de funcionarios públicos. Fruto de esa labor de interpretación casuística, la doctrina y la jurisprudencia suelen admitir que algunos de los criterios utilizables con tal fin son el de comprobar si la supuesta transgresión de un limite en el ejercicio de un derecho fundamental de libertad pública pone o no públicamente en entredicho la autoridad de sus superiores jerárquicos, y el de si tal actuación compromete el buen funcionamiento del servicio».(STC 81/1983)

\section{B. Miembros de las Fuerzas Armadas}

También los límites a la libertad de expresión a los que se hallan sometidos los miembros de las Fuerzas Armadas han sido objeto de varias de las sentencias y Autos del Tribunal Constitucional (ATC 
375/1983, y las Sentencias SSTC 371/1983, 270/1994, 21/1981, 97/1985, 180/1985, 107/1986, 9/1985 entre otras).

La cuestión que se plantea no es otra que la relativa a un conflicto entre el ejercicio que un miembro de las Fuerzas Armadas ha hecho, en su condición de tal, del derecho a la libertad de expresión y opinión que la Constitución garantiza en su art. 20.1 a) de la C.E. y los límites a los que el mismo se encuentra sometido. Se trata, por tanto, de determinar hasta qué punto puede apreciarse que las expresiones por las que pueden ser sancionados los miembros de este colectivo son ejercicio del derecho a la libertad de expresión o, por el contrario, se extralimitan del ámbito constitucionalmente protegido y transgreden los límites que le impone el ordenamiento vigente, en concreto, las normas específicas aplicables a la institución de la que forma parte, resultando, en consecuencia, incardinables en los supuestos en que la Ley Orgánica 12/1985, del Régimen Disciplinario de las Fuerzas Armadas (L.O.R.D.) protege el debido respeto a los órganos y autoridades del Estado, puesto que, dado el tipo disciplinario aplicado, ese es el bien jurídico que se estima dañado.

Para su resolución, debe partirse ineludiblemente de lo que es ya muy reiterada doctrina del Tribunal Constitucional, esto es, que las libertades reconocidas en el art. 20.1 a) y d) de la Constitución no sólo son derechos fundamentales de cada ciudadano, sino que significan el reconocimiento y la garantía de una institución política fundamental, que es la opinión pública libre, indisolublemente ligada al pluralismo político, por lo que trasciende el significado común y propio de los demás derechos fundamentales y, en consecuencia, habría de reconocerse una posición preferente, en razón de su dimensión constitucional, a las libertades contenidas en el art. 20 de la Constitución cuando se ejerciten en conexión con asuntos que sean de interés general y contribuyan a la formación de una opinión pública libre y plural.

Ahora bien, según la doctrina del TC, no cabe considerar que esas libertades sean absolutas o ilimitadas. Por el contrario, su ejercicio está sujeto tanto a límites constitucionalmente expresos, como a otros que puedan fijarse para preservar bienes y derechos constitucionalmente protegidos; si bien, y como precisión necesaria, tampoco podrá atribuirse carácter absoluto a los límites a que ha de someterse el ejercicio de esas libertades: Límites que se configuran como excepcionales ante el reconocimiento constitucional del derecho a la libertad de expresión. Algunos de estos límites son generales y comunes a todos los ciudadanos. Pero también, como ha tenido 
ocasión de señalar el TC, hay sectores o grupos de ciudadanos sometidos a límites específicos, más estrictos, en razón a la función que desempeñan. Determinados funcionarios públicos pueden encontrarse con límites específicos, en razón de la naturaleza del servicio que desempeñan, y que pueden imponerse "ya sea en virtud del grado de jerarquización o disciplina interna a que estén sometidos, que puede ser diferente en cada Cuerpo o categoría funcionarial, ya sea según actúen en calidad de ciudadanos o funcionarios, ya en razón de otros factores que hayan de apreciarse en cada caso, con el fin de comprobar si la supuesta transgresión de un límite en el ejercicio de un derecho fundamental pone o no públicamente en entredicho la autoridad de sus superiores jerárquicos, y el de si tal actuación compromete al buen funcionamiento del servicio" (STC 69/1989). Límites específicos al ejercicio de aquel derecho fundamental, derivados de la condición de funcionario público, que en cuanto restringen su ejercicio también han de ser interpretados restrictivamente (STC 81/1983).

Dentro de las limitaciones a los derechos del art. 20 C.E., deben singularizarse aquellas referentes a los miembros de las Fuerzas Armadas, en atención a las peculiaridades de éstas y las misiones que se les atribuyen. Dadas las importantes tareas que a las Fuerzas Armadas asigna el art. 8.1 C.E., representa un interés de indudable relevancia en el orden constitucional el que las mismas se hallen configuradas de modo que sean idóneas para el cumplimiento de esos cometidos (ATC 375/1983). A tal fin, la atención de las misiones que les encomienda el mencionado precepto constitucional requiere una adecuada y eficaz configuración de las Fuerzas Armadas de la que, entre otras singularidades, deriva su indispensable y específico carácter de organización profundamente jerarquizada, disciplinada y unida. Como consecuencia de ello, y de acuerdo con la doctrina constitucional antes citada, no cabe duda de que el legislador puede introducir determinadas peculiaridades o establecer límites específicos al ejercicio de las libertades reconocidas en la Constitución por los miembros de las Fuerzas Armadas, límites que supondrían una diferenciación respecto del régimen general y común de esas libertades. Este régimen especial puede suponer peculiaridades tanto de orden procedimental (SSTC 21/1981; 97/1985, y 180/1985) como de orden sustantivo, al introducirse previsiones sancionadoras diferentes de las aplicables al resto de los ciudadanos (STC 107/1986), «el legislador puede introducir determinadas peculiaridades en el Derecho Penal militar que supongan una diferenciación del régimen penal común, peculiaridades que hallan su justificación en las exigencias de la or- 
ganización militar», consideración ésta naturalmente aplicable también al régimen disciplinario.

Ha de concluirse, en el sentido de la jurisprudencia citada, que el legislador podrá legítimamente imponer límites específicos al ejercicio de la libertad de expresión de los miembros de las Fuerzas Armadas siempre y cuando esos límites respondan a los principios primordiales y los criterios esenciales de organización de la institución militar, que garanticen no sólo la necesaria disciplina y sujeción jerárquica, sino también el principio de unidad interna, que excluye manifestaciones de opinión que pudieran introducir formas indeseables de debate partidista dentro de las Fuerzas Armadas, o, en términos de la STC 97/1985, "disensiones y contiendas dentro de las Fuerzas Armadas, las cuales necesitan imperiosamente, para el logro de los altos fines que el art. 8.1 de la C.E. les asigna, una especial e idónea configuración». (STC 371/1993)

\section{c. Fuerzas y Cuerpos de Seguridad del Estado}

Han sido varias las Sentencias del Tribunal Constitucional $(81 / 1983,69 / 1989$ y la $270 / 1994)$ que han versado acerca de las limitaciones que existen sobre la libertad de expresión respecto de los miembros de las Fuerzas y Cuerpos de Seguridad del Estado.

En palabras del TC: « Según la Constitución en su art. 103.1, la Administración actúa de acuerdo con el principio de jerarquía, y este principio institucional se convierte en deber «de respeto y obediencia a las autoridades y superiores jerárquicos" para los funcionarios sujetos al Reglamento orgánico de la Policía. De modo coherente con tal deber el art. 207 del mismo Reglamento considera como faltas graves en su apartado a) «la desobediencia o irrespetuosidad a los superiores o autoridades», el c) «las manifestaciones públicas de crítica o disconformidad respecto de las decisiones de los superiores". La estructura interna del Cuerpo Superior de Policía, y la misión que el art. 104.1 de la C. E. atribuye entre otros, a dicho Cuerpo, obligan a afirmar que la crítica a los superiores, aunque se haga en uso de la calidad de representante y autoridad sindical y en defensa de los sindicados, deberá hacerse con la mesura necesaria para no incurrir en vulneración a este respeto debido a los superiores y para no poner en peligro el buen funcionamiento del servicio y de la institución policial. Todos los derechos, al ser ejercidos, entran en concurrencia con otros bienes y derechos también dignos de tutela. El normal funcionamiento del Cuerpo Superior de Policía exige que sus miem- 
bros estén «sujetos» en su actuación profesional a los principios de jerarquía y subordinación», para hacer posible la garantía de la seguridad ciudadana y la protección de los derechos y deberes de los citados ciudadanos y que el art. 104.1 de la C. E. atribuye a las Fuerzas y Cuerpos de seguridad, entre los que se encuentra el C. S. P., y esos bienes jurídicamente protegidos se pondrían en peligro. (STC 81/1983). 